\title{
Pembelajaran Menulis Aksara Jawa yang Partisipatoris Menggunakan Video Tutorial dengan Memraktikkan Tracing dan Menulis di Pasir
}

\author{
Martha Lusiana ${ }^{1}$, Alviani Permata ${ }^{2}$, Raden Bima Adi $^{3}$ \\ Koordinatorat Mata Kuliah Humaniora, Universitas Kristen Duta Wacana \\ ${ }^{1}$ marthalusi@staff.ukdw.ac.id \\ 2alviani@staff.ukdw.ac.id \\ 33bima@staff.ukdw.ac.id
}

\begin{abstract}
Abstrak - Kegiatan pembelajaran bahasa tidak berjalan efektif jika tidak mengandung unsur praktik yang diulang. Oleh karena itu, diperlukan suatu rancangan pembelajaran bahasa yang partisipatoris, sehingga siswa mampu meningkatkan kompetensinya dalam berkomunikasi dengan bahasa yang sedang dipelajari. Kegiatan pengabdian kepada masyarakat ini bertujuan untuk memberikan pelatihan kepada orang tua dan pendamping anak kelas IV Sekolah Dasar di rumah agar orang dewasa dapat berpartisipasi dalam proses belajar menulis aksara Jawa. Pembelajaran ini menggunakan alat peraga yang diadaptasi dari pembelajaran bahasa oleh Montessori. Luaran kegiatan ini adalah video tutorial yang memperlihatkan langkah awal belajar menulis aksara Jawa dengan cara melakukan tracing dan menulis di pasir. Selain itu, di dalam video ini, juga diperlihatkan detail proses pendampingan belajar dari Montessori. Video ini dapat diakses dan dipraktikkan dengan mudah di rumah oleh pendamping bersama anak, agar anak bisa lebih bersemangat dan senang belajar menulis aksara bahasa Jawa. Di samping menambah alternatif aktivitas belajar, orang tua dan pendamping dapat semakin terlibat dalam proses pemerolehan bahasa dalam diri anak. Dengan mengerjakan aktivitas yang menyenangkan, jumlah anak atau siswa yang menyukai kegiatan menulis aksara bahasa Jawa pun dapat meningkat demi proses pelestariannya.
\end{abstract}

Kata kunci-aksara Jawa, partisipatoris, video tutorial, tracing, menulis di pasir.

Abstract-Language learning activities are not effective if they do not contain elements of repeated practice. Therefore, a participatory language learning design is needed, so that students are able to improve their competence in communicating with the language being studied. This community service activity aims to provide training to parents and assistants of fourth grade elementary school children at home so that adults can participate in the process of learning to write Javanese characters. This learning uses teaching aids adapted from language learning by Montessori. The output of this activity is a video tutorial that shows the initial steps of learning to write Javanese characters by tracing and writing on the sand. In addition, this video also shows the details of the learning mentoring process from Montessori. This video can be accessed and practiced easily at home by the companion with the child, so that the child can be more enthusiastic and happier to learn to write Javanese characters. In addition to adding alternative learning activities, parents and companions can be more involved in the process of acquiring language in children. By doing fun activities, the number of children or students who like writing Javanese characters can also increase for the sake of the preservation process.

Keywords - Java Script, participatory, tutorial video, tracing, writing on sand.

\section{PENDAhUluan}

Bahasa merupakan akar dari transformasi terhadap lingkungan yang disebut peradaban (Montessori, [2]). Bahasa, yang merupakan salah satu unsur dari kebudayaan, menjadi alat manusia dalam berbagi pengetahuan dan informasi, juga dalam belajar. Melalui bahasa, seseorang dapat mengenal cerita-cerita yang berkembang dalam masyarakatnya, puisi atau lagu-lagu yang diciptakan, serta percakapan-percakapan yang terjadi setiap hari. Oleh karena begitu banyaknya hal yang diciptakan manusia 
dengan menggunakan bahasa, bahasa menjadi unsur paling utama dari perbedaan antara manusia dan makhluk lainnya. Dengan demikian, mempelajari bahasa, apa pun itu, akan membantu manusia mengenali diri sendiri dan posisinya dalam konteks budaya yang dihadapi. Dalam kegiatan pengabdian ini, pembelajaran menulis aksara Jawa dijadikan fokus karena diyakini dapat menjadi sarana dalam memahami budaya bagi seorang anak yang tinggal dalam konteks Jawa.

Pembelajaran menulis aksara Jawa menjadi tantangan tersendiri, baik bagi guru maupun peserta didiknya. Pada kurikulum 2013, pembelajaran menulis aksara Jawa mulai diberikan di kelas III tingkat Sekolah Dasar (SD). Pada tingkat ini, anak mulai mempelajari aksara legena, yakni aksara Jawa hanacaraka yang belum mendapatkan sandhangan atau pasangan.

\begin{tabular}{|c|c|c|c|c|}
\hline \multicolumn{5}{|c|}{ AKSARA JAWA } \\
\hline )ा & $\mathbb{H}$ & |小] & $\Pi$ & กஜி \\
\hline ha & na & $\mathrm{ca}$ & $\mathrm{ra}$ & ka \\
\hline กด & Џ! & ลา & |ు & mn \\
\hline da & ta & sa & wa & la \\
\hline గी & חו & $\mathbb{R} \mathbf{R}$ & חป & IITI \\
\hline $\mathrm{pa}$ & dha & ja & ya & nya \\
\hline ઝી & $\mathbf{m}$ & 几l】 & $n_{q}^{m}$ & Ł.】 \\
\hline $\mathrm{ma}$ & ga & ba & tha & nga \\
\hline
\end{tabular}

Gambar 1. Dua puluh (20) aksara Jawa hanacaraka (legena, yakni tanpa sandahangan atau pasangan)

Bagi siswa, menulis aksara Jawa cukup sulit dipelajari karena aksara Jawa hampir sudah tidak dipakai dalam kehidupan sehari-hari sebagai sarana baca tulis, hanya terbatas pada simbol kedaerahan, baik pada nama jalan ataupun dalam kegiatan dan gedung-gedung pemerintahan. Jadi, posisi aksara Jawa bagi anak-anak saat ini dapat dianggap sebagai bahasa asing.

Masalah lainnya adalah bahwa pembelajaran menulis aksara Jawa dinilai cenderung monoton dan memaksa anak untuk menghafal bentuk dan aturan penulisannya. Selain itu, media pembelajaran yang tersedia masih kurang atraktif, interaktif, dan modern, sehingga kurang mampu menarik minat siswa untuk belajar menulis aksara Jawa. Menurut penelitian yang dilakukan BAPEDA DIY tahun 2004 mengenai kondisi pembelajaran bahasa Jawa di lapangan, 93\% guru di tingkat SD dan SMP hanya menggunakan metode ceramah dalam setiap penyampaian materi pembelajaran. Selain itu, media pembelajaran terbatas pada media tradisional, seperti gambar di dinding dan kaset tembang [1].

Berbagai macam metode sudah ditawarkan untuk meningkatkan minat dan keterampilan anak dalam menulis aksara Jawa. Hartanto [4] membuat aplikasi yang dapat membantu anak mempelajari aksara Jawa. Aplikasi ini memiliki fitur untuk mengenal aksara dasar, pasangan, dan sandhangan, beserta cara menuliskannya. Selain materi aksara Jawa, aplikasi ini telah dilengkapi dengan menu pembelajaran nama hewan serta fitur evaluasi untuk mengetahui kemampuan anak. Aplikasi pembelajaran ini juga disertai gambar dan suara yang sudah disesuaikan dengan tingkat pendidikan anak, yakni kelas tiga hingga enam SD. Sutarsih [7], dalam penelitiannya, menawarkan teknik pemetaan dan pola dengan membuat titik-titik yang membentuk aksara dalam kegiatan belajar menulis aksara Jawa. Sebelumnya, ia terlebih dahulu mengidentifikasi kendala dan kesulitan yang dialami oleh siswa melalui guru bahasa Jawa kelas III SD di Kota Semarang. Anak-anak tersebut mengalami kesulitan untuk membedakan aksara yang memiliki kesamaan bunyi dan bentuk, terlebih bila soal diberikan oleh guru secara lisan dengan metode dikte.

Berdasarkan metode dan media yang telah ditawarkan dan diteliti, seluruh upaya pembelajaran tersebut diberikan di sekolah hanya dengan melibatkan guru dan siswa. Padahal, pembelajaran menulis aksara Jawa perlu terusmenerus dilakukan agar anak tetap memiliki minat dan keterampilan dalam menulis aksara Jawa. Dalam Pengabdian kepada Masyarakat (PkM) ini, dibuat video tutorial pembelajaran menulis aksara Jawa sebagai pendamping belajar anak di rumah. Video tutorial ini ditujukan untuk para orang tua atau orang dewasa yang mendampingi anak agar mereka dapat melakukan aktivitas yang menyenangkan dan bermakna bersama dan bagi anak. Hal ini penting dalam pembelajaran bahasa yang sudah jarang digunakan sehari-hari serta memiliki aksara yang berbeda dengan bahasa yang umum digunakan.

Melalui video tutorial tersebut, pembelajaran menulis aksara Jawa dapat terus-menerus dilakukan, agar anak tetap memiliki minat dan keterampilan dalam menulis aksara Jawa. Dengan strategi yang lebih partisipatoris dan menggunakan media pembelajaran, video ini diharapkan dapat menjadi sarana belajar yang menyenangkan karena menggunakan alat peraga yang kreatif dan inovatif, juga mampu meningkatkan keterlibatan orang tua dan pendamping dalam pembelajaran bahasa bagi anak.

\section{METODE}


Metode-metode pembelajaran menulis aksara Jawa selama ini masih dinilai searah dan tidak berpusat pada siswa. Mitra dalam kegiatan pengabdian ini adalah Kalyca Montessori School di Yogyakarta. Bersama sekolah Kalyca, pengabdian ini mencoba menyediakan cara belajar menulis aksara Jawa dengan pendekatan partisipatoris yang berbasis siswa. Metode yang digunakan dalam pembelajaran menulis aksara Jawa diadopsi dari model Montessori sebagai model yang dipakai di sekolah tersebut. Maria Montessori adalah seorang dokter perempuan pertama Italia yang menyusun suatu kurikulum, antara lain mengenai perkembangan bahasa anak usia dini. Di dalam kurikulumnya, ia menawarkan metode partisipatoris yang membebaskan anak, misalnya dengan memberikan kesempatan pada anak untuk melakukan kesalahan ketika belajar (Afifah, [3]).

Pengabdian ini telah menghasilkan video tutorial pembelajaran menulis aksara Jawa dengan alat peraga yang mudah didapat dan dibuat. Berikut ini adalah bagan kerangka pemecahan masalah.

\begin{tabular}{|c|c|c|c|c|}
\hline $\begin{array}{c}\text { Identifikasi } \\
\text { Masalah }\end{array}$ & Tujuan & Input & Proses & Luaran \\
\hline \multirow{10}{*}{$\begin{array}{l}\text { Pembelajaran } \\
\text { menulis } \\
\text { aksara Jawa } \\
\text { yang monoton } \\
\text { bagi anak }\end{array}$} & \multirow{6}{*}{$\begin{array}{c}\text { Memberi contoh } \\
\text { pembelajaran } \\
\text { mcnulis aksara } \\
\text { Jawa dingaun } \\
\text { pendckatan yang } \\
\text { partisipatoris yano } \\
\text { menyenangkan }\end{array}$} & Matcri aksara & \multirow{3}{*}{\begin{tabular}{|l} 
Menyusun modul \\
dan kontcn vidco \\
pembelajaran
\end{tabular}} & \\
\hline & & \begin{tabular}{|l} 
Jassa \\
\end{tabular} & & \\
\hline & & \multirow{2}{*}{\begin{tabular}{|l|} 
Materi nilai- \\
nilai budayat \\
Jiswa \\
\end{tabular}} & & \\
\hline & & & & \\
\hline & & \multirow{2}{*}{$\begin{array}{c}\text { Bahan ajar } \\
\text { pembeliajaran }\end{array}$} & \multirow{2}{*}{$\begin{array}{l}\text { Memproduksi video } \\
\text { pembclajarran }\end{array}$} & \\
\hline & & & & \\
\hline & & & & \\
\hline & & & $\begin{array}{l}\text { Mendemonstrasikan } \\
\text { video pembelajaran } \\
\text { kepada para }\end{array}$ & \\
\hline & & & pendamping anak & \multirow{2}{*}{ 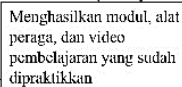 } \\
\hline & & & & \\
\hline
\end{tabular}

Gambar 2. Bagan Kerangka Pemecahan Masalah

Pada tabel di atas, hal yang perlu diperhatikan dalam membuat video tutorial ini tidak hanya mencakup cara menuliskan aksara Jawa, tetapi juga perlu menyisipkan materi aksara Jawa dan nilai-nilai pembelajaran yang terkandung di dalamnya. Dengan demikian, orang tua atau pendamping anak yang menonton video ini tidak hanya mendapatkan pelatihan cara mengajarkan dan menuliskan aksara Jawa, namun juga memeroleh pengetahuan penting lainnya, baik mengenai aksara dan budaya Jawa maupun dalam pendampingan. Hal tersebut perlu diperhitungkan karena dapat meningkatkan kualitas relasi antara orang tua atau pendamping dan anak saat memraktikkan aktivitas di dalam video ini. Seturut dengan Pisarenko [8], salah satu fungsi dari video tutorial adalah untuk memberikan informasi dalam bentuk pelatihan. Jadi, pelibatan siswa sekolah Mitra di dalam video yang menunjukkan cara melakukan tracing dan menulis aksara Jawa di pasir dapat dijadikan model bagi peserta pelatihan dengan menonton video yang bersangkutan.
Untuk mewujudkan hal tersebut, ada beberapa tahap yang telah dilakukan.

1. Penyusunan Modul dan Pembuatan Alat Peraga,

2. Pembuatan Skrip/Naskah Video, serta

3. Pelaksanaan Uji Coba dan Pembuatan Video.

\section{HASIL DAN PEMBAHASAN}

Kegiatan PkM yang berjudul "Pembelajaran Menulis Aksara Jawa kepada Pendamping Anak di Rumah dengan Pendekatan Yang Partisipatoris Melalui Video" ini seperti yang direncanakan adalah membuat luaran berupa video tutorial. Adapun pembahasan pada tiap-tiap langkahnya adalah sebagai berikut.

\section{A. Tahap Penyusunan Modul dan Pembuatan Alat Peraga}

Tahap ini dimulai dengan melakukan pendekatan dengan mitra, yakni Kalyca Montessori School Yogyakarta, untuk mendiskusikan ide pengembangan pembelajaran menulis aksara Jawa bagi para orang tua atau pendamping anak dengan mengadopsi pendekatan Montessori. Selain itu, pada tahap ini, ditetapkan pula rencana kerja sama dengan mitra. Ketika pihak mitra telah menyatakan kesetujuannya, diadakan pertemuan untuk mendiskusikan dan melaksanakan kolaborasi dalam penyediaan materi bacaan dasar sebagai bahan dalam membuat modul pembelajaran.

Dalam menyusun modul, pustaka, dan materi pembelajaran diperoleh dari sekolah Mitra agar sesuai dengan basis pembelajaran bahasa di sekolah tersebut. Hal itu dilakukan agar guru dapat dengan mudah mengikuti proses dan memraktikkannya karena sudah terbiasa dengan modul yang tersedia di sekolah.

Modul pembelajaran yang disiapkan ini berupa pengetahuan dasar mengenai aksara Jawa, seperti asal-usul dan karakternya. Hal ini dianggap penting agar orang tua atau pendamping yang tidak berasal dari Jawa atau tidak memiliki pengetahuan mengenai aksara Jawa dapat mengerti dan membagikan pengetahuan tersebut kepada anak sembari memraktikkan video pembelajaran.

Di dalam modul pembelajaran, ihwal alat peraga pun disampaikan. Pada tahap ini, bahan dan alat-alat untuk menjadi alat peraga mulai disiapkan dan dibuat. Di dalam proses ini, mitra memberikan banyak pengetahuan penting mengenai bahan-bahan yang ramah bagi anak sesuai dengan model Montessori, seperti memilih kain flanel dan warnanya untuk kegiatan tracing, serta menentukan ukuran nampan dan jenis pasir pantai untuk kegiatan menulis aksara di pasir. 


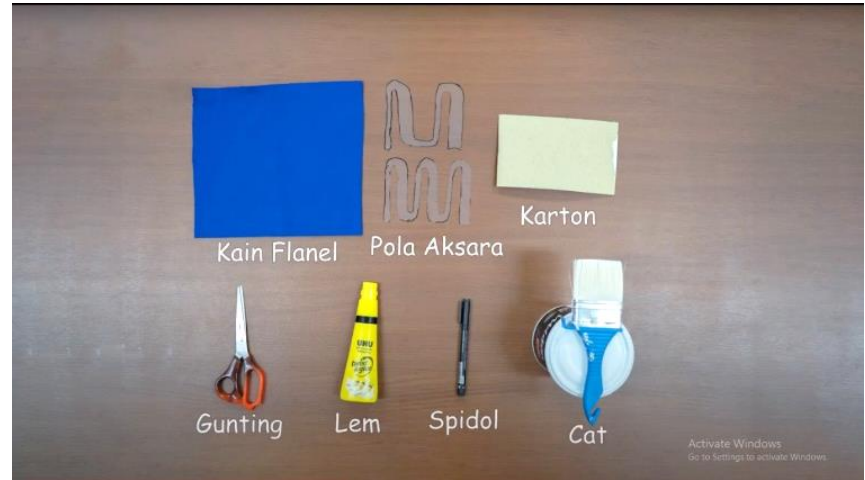

Gambar 3. Bahan dan alat untuk membuat alat peraga Tracing

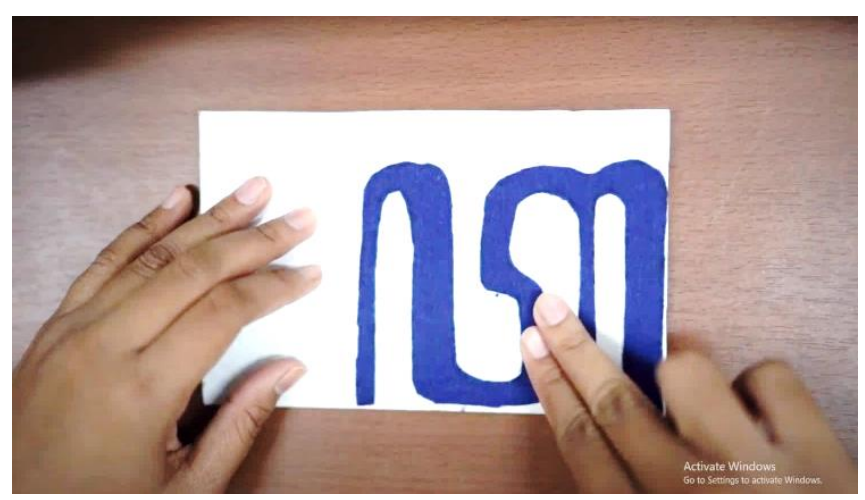

Gambar 4. Alat peraga tracing yang sudah jadi.

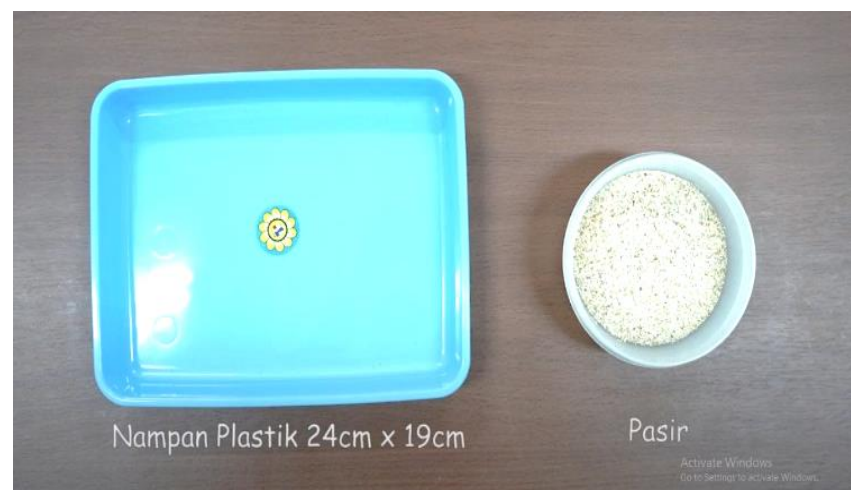

Gambar 5. Alat peraga untuk kegiatan menulis aksara di pasir

Aktivitas pembelajaran menulis aksara Jawa ini mengedepankan tiga area belajar, yakni sensori, bahasa, dan budaya. Ruang sensori dirancang untuk memberi pengalaman berbeda kepada anak. Di ruang ini, aksaraaksara Jawa dibentuk dengan bahan-bahan yang berbeda sehingga anak akan belajar mengenai warna dan tekstur melalui sentuhan dan rabaan. Di dalam pembelajaran ini juga, ruang bahasa dijadikan dasar untuk mengekspresikan aktivitas berbahasa, baik dalam hal menulis dan membunyikan aksara, mendengar, maupun menggunakan kosa kata lainnya dalam bahasa Jawa. Dalam proses ini disadari bahwa belajar menulis aksara Jawa bukanlah hal yang umum dilakukan mengingat bahasa Jawa di masa kini bukan pilihan siswa untuk dipraktikkan dalam pergaulan sehari- hari, terlebih lagi menulis dengan menggunakan aksara Jawa. Akan tetapi, ada keuntungan yang besar bagi anak-anak yang menerapkan praktik berbahasa lebih dari satu atau menjadi bilingual. Penelitian menunjukkan adanya peningkatan IQ (Tim Redaksi,[9]), pemahaman terhadap penyelesaian konflik yang lebih baik, dan menjadi lebih kreatif. (Marian dan Shook, [10]). Yang terakhir, pelibatan area belajar pada ruang budaya sekaligus akan melibatkan narasi dan nilai-nilai budaya Jawa. Hal ini pun sesuai dengan penelitian Marian dan Shook di atas, bahwa belajar bahasa lain meningkatkan kemampuan untuk menjelajahi budaya melalui bahasa aslinya. Dengan begitu, tujuan Pemerintah Daerah melalui peraturan Gubernur untuk menanamkan nilai-nilai Jawa dapat dicapai.

\section{B. Pembuatan Skrip/Naskah Video}

Sebelum dilakukan pembuatan video, skrip atau naskah video perlu didiskusikan dan dibuat terlebih dahulu. Bagian ini memiliki tantangan yang cukup besar, karena penyusun perlu membayangkan proses tutorial itu serinci mungkin, mulai dari runtutan cerita, detail setiap urutan, tokoh pelaksana, sampai dengan durasi yang dibutuhkan.

Runtutan cerita dalan naskah ini terdiri atas salam pembuka, penjelasan singkat mengenai aksara Jawa, lalu masuklah pada dua aktivitas utama, yakni tracing aksara pada kain flanel dan menulis aksara di pasir. Setelah itu, diberikan ide aktivitas tahap lanjut, yakni membuat satu dari dua aksara legena, seperti baya (buaya) atau lawa (kelelawar), agar anak bisa membayangkan proses penulisan aksara saat membentuk suatu kata yang mudah dikenali anak.

Di dalam naskah video, pada setiap runtutan cerita tersebut, ada detail-detail yang perlu diperhatikan, seperti musik latar dan penerapan subtitle supaya video tutorial ini mudah diikuti oleh berbagai kalangan. Selain itu, cara membuat alat peraga tidak diperlihatkan secara terperinci karena memperhatikan durasi keseluruhan video.

Selain runtutan cerita, hal lain yang perlu didiskusikan dalam menyusun naskah adalah tokoh pemerannya. Di dalam video ini terdapat 2 (dua) personel yang akan berperan sebagai pendamping dan anak. Pendamping, dalam video ini, diperankan langsung oleh guru Bahasa Jawa dari sekolah Mitra yang sudah memahami penulisan aksara Jawa dan model pembelajaran Montessori. Sementara itu, anak yang dipilih adalah salah satu murid sekolah Mitra kelas IV SD yang sudah pernah menerima materi aksara bahasa Jawa. Meskipun begitu, video ini dapat dipraktikkan bersama anak yang lebih muda kelasnya untuk memperkenalkan gerakan tangan dalam menulis aksara Jawa. 


\section{Pelaksanaan Uji Coba dan Pembuatan Video}

Sebelum melakukan pembuatan video, tim penyusun dan pemeran video melakukan uji coba terlebih dahulu. Pada tahap ini sempat ada kekhawatiran ada penolakan dari pemeran yang masih anak-anak. Namun, kekhawatiran itu tidak terjadi. Pemeran anak cukup antusias membantu dan memraktikkan aktivitas menulis aksara Jawa. Dengan didampingi guru di sekolah yang sudah dikenalnya, proses uji coba ini berjalan lancar. Pada tahap uji coba ini, kedua pemeran melakukan geladi bersih atas naskah video yang sudah dibuat. Dari geladi bersih tersebut, ada beberapa detail yang perlu direvisi demi menyajikan tutorial yang lebih efektif.

Selanjutnya, tahap perekaman video tutorial yang awalnya direncanakan satu hari, ternyata membutuhkan waktu tambahan. Hari pertama adalah merekam gambar dan suara oleh anak dan pendamping untuk pembelajaran menulis aksara Jawa dengan alat peraga yang sudah dibuat. Di hari pertama itu juga dilakukan rekaman salam pembuka dan penutup oleh pendamping. Hari kedua dibutuhkan untuk merekam suara di bagian-bagian tertentu, seperti penjelasan tentang aksara Jawa, penyebutan bahan dan alat peraga, penjelasan tentang tujuan penting dari kedua aktivitas, serta kegiatan tahap lanjut yang diusulkan.

Aktivitas utama dalam video tutorial ini adalah tracing dan menulis aksara di pasir. Tracing merupakan kegiatan menelusuri aksara dengan dua jari, sedangkan menulis di pasir adalah kegiatan menuliskan aksara di pasir dalam nampan plastik dengan menggunakan satu jari.

Baik pada aktivitas tracing, maupun menulis aksara di pasir, pendamping duduk di samping anak. Hal ini dilakukan agar pendamping dapat langsung memberikan perbaikan saat anak melakukan kesalahan dalam memraktikkan aktivitas.

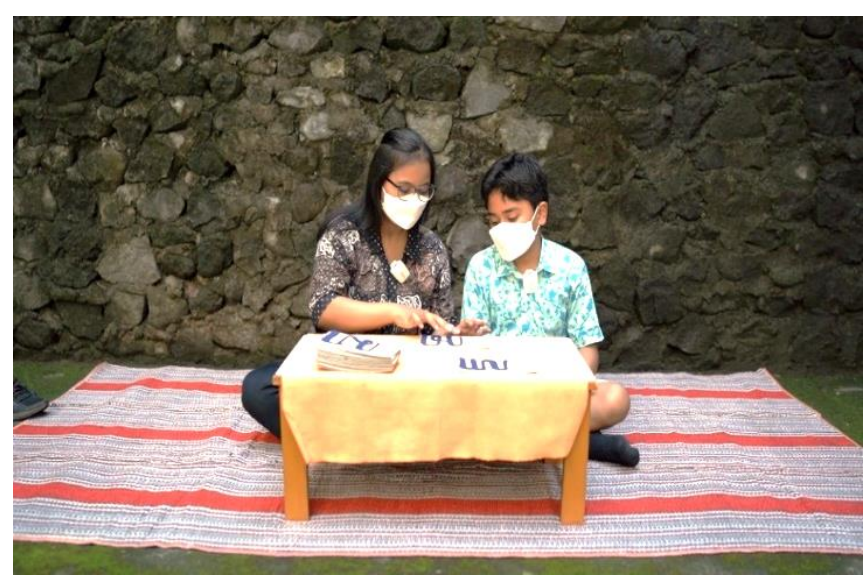

Gambar 6. Pendamping duduk di samping anak pada kegiatan tracing.

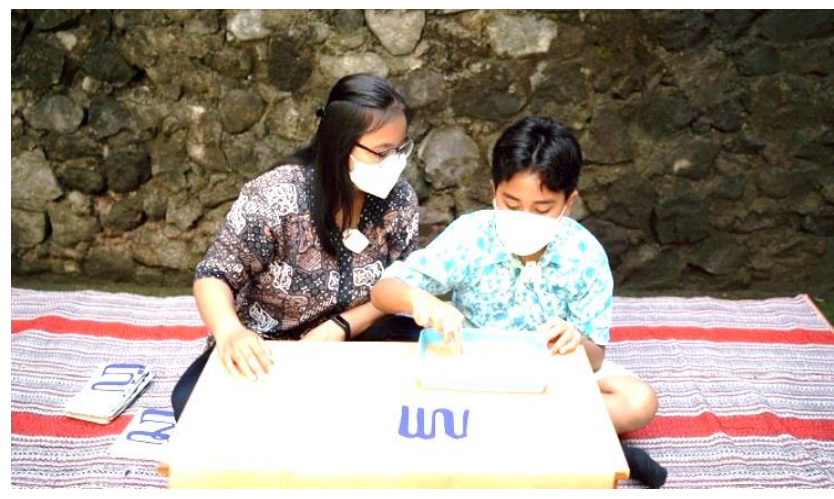

Gambar 7. Pendamping duduk di samping anak pada kegiatan menulis aksara di pasir.

Ketika melakukan aktivitas tracing dan menuliskan aksara di pasir, pendamping dan siswa perlu membunyikan aksara yang di-tracing dan dituliskan di pasir. Hal ini dilakukan oleh siswa setelah guru membunyikan. Setiap aksara dalam kegiatan, baik tracing maupun menulis di pasir, dibunyikan sebanyak tiga kali. Aksara Jawa ini telah memiliki bunyi vokal dan konsonan yang menyatu, sehingga siswa tidak memiliki kesulitan dalam mengucapkannya. Dalam praktiknya, siswa akan melakukan penelusuran aksara (tracing) dan penulisan aksara di atas alat peraga sambil membunyikan suara gabungan konsonan-vokal terkait. Melalui cara membunyikan setiap aksara, siswa menyadari bahwa sebuah aksara dihasilkan oleh bunyi individual yang telah diketahuinya, demikian pula nantinya, kata-kata yang dihasilkan.

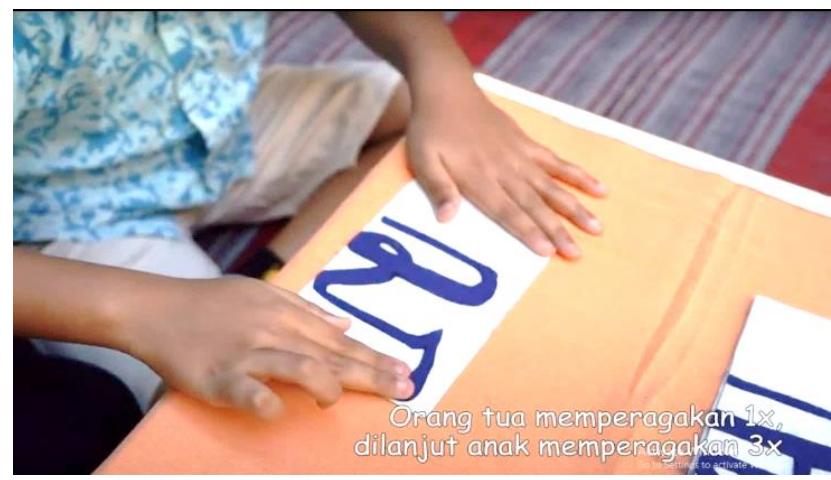

Gambar 8. Anak memraktikkan tracing aksara Jawa 


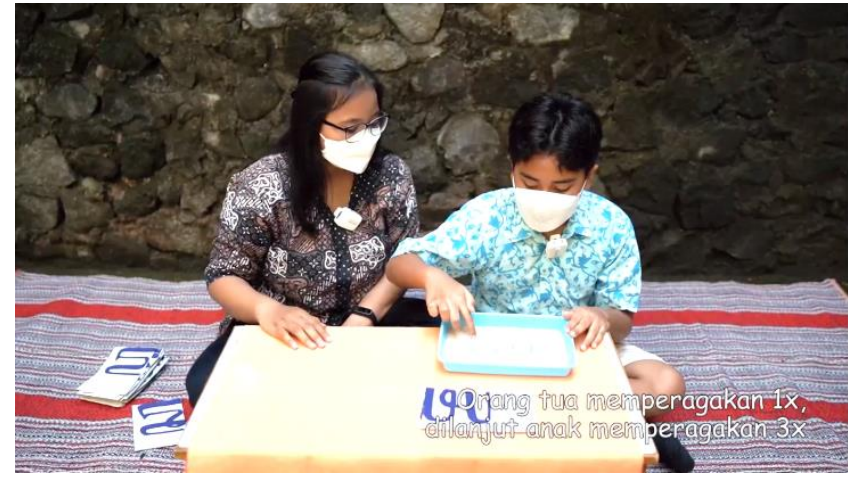

Gambar 9. Anak memraktikkan aktivitas menulis aksara di pasir

\section{KESIMPULAN}

Pengabdian kepada Masyarakat ini merupakan kegiatan membuat video tutorial pembelajaran menulis aksara Jawa sebagai pendamping belajar siswa di rumah. Di dalam kegiatan ini, video yang dibuat memperlihatkan dua aktivitas utama, yakni tracing dengan menggunakan kain flanel dan aktivitas menulis aksara di pasir. Kedua aktivitas ini dapat diikuti dengan mudah oleh orang tua atau pun pendamping lainnya agar anak bisa belajar menulis aksara Jawa di rumah dengan cara yang menyenangkan. Di video ini, juga terdapat pengetahuan dasar mengenai aksara Jawa sehingga orang tua atau pun pendamping juga dapat membagikannya kepada anak saat belajar bersama.

Melalui strategi yang lebih partisipatoris dan menggunakan media pembelajaran, video ini diharapkan dapat dijadikan sarana belajar yang menyenangkan. Hal penting lain adalah meningkatnya keterlibatan orang tua dan pendamping anak dalam tumbuh kembang anak, terutama dalam pemerolehan bahasa. Di samping itu, dengan mengunggah video tersebut ke akun media sosial milik sekolah yang menjadi mitra, hal itu dapat meningkatkan peran aktif sekolah mitra dan masyarakat pada umumnya dalam pelestarian Bahasa dan Aksara Jawa di Yogyakarta sesuai himbauan dari Pimpinan Pelestari Budaya, Daerah Istimewa Yogyakarta.

Belajar bahasa tidak pernah merugikan pembelajarnya. Melaluinya seseorang mampu mengenal budaya yang tersimpan dalam bahasa yang dipelajari. Peradaban dibangun melalui Bahasa. Dengan belajar menuliskan aksara Jawa, para siswa akan mengenal cerita di balik aksara yang akan mengenalkan mereka lebih jauh pada filosofi budaya Jawa.

Akan halnya pembuatan video tutorial, dibutuhkan bantuan seorang pembuat video (videographer) yang berpengalaman, sehingga dapat memberi saran yang kadang tidak terpikirkan oleh pemesan video. Penceritaan yang runut yang mencerminkan proses tutorial yang lancar sangat penting demi kelancaran proses pembelajaran melalui video yang menggantikan seorang tutor secara fisik. Akhirnya, video tutorial menuliskan aksara Jawa yang disediakan kiranya dapat membantu siswa memperpanjang waktu belajarnya di rumah dengan senang hati.

\section{UCAPAN TERIMA KASIH}

Tim PkM Pembelajaran Menulis Aksara Jawa ini menghaturkan terima kasih kepada Lembaga Penelitian dan Pengabdian kepada Masyarakat (LPPM) dan juga Koordinatorat Mata Kuliah Humaniora (MKH) UKDW atas dukungan dana untuk menyelenggarakan kegiatan ini. Diucapkan juga terima kasih kepada Kalyca Montessori School atas kesediannya menjadi Mitra. Tidak lupa juga, ucapan terima kasih diberikan kepada Wahyu Setiawan, mahasiswa UKDW, atas kesediannya menjadi asisten; Bajra Nataakasa Kodrat, murid sekolah Kalyca, atas kesediaannya menjadi talent atau pemeran anak dalam video; juga Andreas Susilo Dinata, mahasiswa UKDW, atas kerja sama sebagai videografer dalam kegiatan ini.

\section{DAFTAR PUSTAKA}

[1] M. Montessori, The Absorbent Mind, Yogyakarta: Pustaka Pelajar, 1995.

[2] D. N. Afifah and Kuswanto, "Membedah Pemikiran Maria Montessor pada Pendidikan Anak Usia Dini," Pedagodi: Jurnal Anak Usia Dini dan Pendidikan Anak Usia Dini, Vols. Volume 6, Nomer 2, Agustus 2020, pp. 57-68, 2020.

[3] V. I. Ekowati, "Perubahan Sistem Pembelajaran Aksara Jawa," in Seminar Nasional Pembelajaran Bahasa dan Sastra Daerah dalam Kerangka Budaya Jawa, 8 September 2007, Yogyakarta, 2007.

[4] M. Hartanto, "Pembelajaran Aksara Jawa untuk Anak Kelas 3-6 Sekolah Dasar," Fakultas Teknik UBAYA, Surabaya, 2012.

[5] Peraturan Gubernur Daerah Istimewa Yogyakarta (DIY) Nomer 64 Tahun 2013, [Online]. Available: https://peraturan.bpk.go.id/Home/Details/21626. [Accessed $12 \mathrm{Mei}$ 2021].

[6] Tim Redaksi, "Program Digitalisasi Bahasa dan Aksara Jawa," Kompas, p. 8, 19 Oktober 2020.

[7] Sutarsih, "Pembelajaran Menulis Aksara Jawa Kelas III Sekolah Dasar," Aksara, Vols. Volume 27, Nomer 1, pp. 65-72, 2015.

[8] V. Pisarenko, "Teaching a Foreign Language Using Videos," Social Science, Vols. Vol. 6, no. 4, Oktober, p. 125, 2017.

[9] Tim Redaksi, "Being Bilingual Boosts IQ in Children, Talking in Native Language At Home Associated With Higher Intelligence," 24 Agustus 2018. [Online]. Available: https://www.indiatoday.in/educationtoday/news/story/bilingualism-boosts-iq-native-language-higherintelligence-1322467-2018-08-24. [Accessed 25 Oktober 2021]

[10] V. Marian and A. Shook, "The Cognitive Benefits of Being Bilingual," Cerebrum, Vols. September-Oktober, p. 13, 2012. 